OPEN ACCESS

Edited by:

Regis Bernardo Brandim Gomes, Oswaldo Cruz Foundation (Fiocruz),

Brazil

Reviewed by: Carlo José Freire Oliveira, Universidade Federal do

Triângulo Mineiro, Brazil

Iva Kolarova

Charles University, Czechia

${ }^{*}$ Correspondence:

Valeria Aoki

valeria.aoki@gmail.com

Specialty section:

This article was submitted to

Parasite and Host

a section of the journal

Frontiers in Cellular and

Infection Microbiology

Received: 20 December 2021 Accepted: 02 February 2022

Published: 25 February 2022

Citation:

Aoki V, Abdeladhim M, Li N, Cecilio P, Prisayanh P, Diaz LA and Valenzuela JG (2022) Some

Good and Some Bad: Sand Fly Salivary Proteins in the Control of Leishmaniasis and in Autoimmunity. Front. Cell. Infect. Microbiol. 12:839932. doi: 10.3389/fcimb.2022.839932

\section{Some Good and Some Bad: Sand Fly Salivary Proteins in the Control of Leishmaniasis and in Autoimmunity}

\author{
Valeria Aoki ${ }^{{ }^{*}}$, Maha Abdeladhim ${ }^{2}$, Ning Li $^{3}$, Pedro Cecilio ${ }^{4}$, Phillip Prisayanh ${ }^{3}$, \\ Luis A. Diaz ${ }^{3}$ and Jesus G. Valenzuela ${ }^{2}$ \\ ${ }^{1}$ Department of Dermatology, Faculdade de Medicina da Universidade de São Paulo (FMUSP), Universidade de Sao Paulo, \\ Sao Paulo, Brazil, 2 Vector Molecular Biology Section, Laboratory of Malaria and Vector Research, National Institute of Allergy \\ and Infectious Diseases, National Institutes of Health, Rockville, MD, United States, ${ }^{3}$ Department of Dermatology, University \\ of North Carolina at Chapel Hill, Chapel Hill, NC, United States, ${ }^{4}$ Vector Biology Section, Laboratory of Malaria and Vector \\ Research, National Institute of Allergy and Infectious Diseases, National Institutes of Health, Rockville, MD, United States
}

Sand flies are hematophagous insects responsible for the transmission of vector-borne diseases to humans. Prominent among these diseases is Leishmaniasis that affects the skin and mucous surfaces and organs such as liver and spleen. Importantly, the function of blood-sucking arthropods goes beyond merely transporting pathogens. The saliva of vectors of disease contains pharmacologically active components that facilitate blood feeding and often pathogen establishment. Transcriptomic and proteomic studies have enumerated the repertoire of sand fly salivary proteins and their potential use for the control of Leishmaniasis, either as biomarkers of vector exposure or as anti-Leishmania vaccines. However, a group of specific sand fly salivary proteins triggers formation of cross-reactive antibodies that bind the ectodomain of human desmoglein 1, a member of the epidermal desmosomal cadherins. These cross-reactive antibodies are associated with skin autoimmune blistering diseases, such as pemphigus, in certain immunogenetically predisposed individuals. In this review, we focus on two different aspects of sand fly salivary proteins in the context of human disease: The good, which refers to salivary proteins functioning as biomarkers of exposure or as anti-Leishmania vaccines, and the bad, which refers to salivary proteins as environmental triggers of autoimmune skin diseases.

Keywords: sand fly, salivary proteins, immunogenicity, cellular immunity, antibodies, autoimmunity

\section{INTRODUCTION}

Sand flies are phlebotomine arthropods and the main vectors of Leishmania parasites; sand flies are also relevant in other vector-borne diseases (VBDs) (Abdeladhim et al., 2014). Sand flies are distributed worldwide. They comprise six genera, two that are associated with human disease Phlebotomus in the Old World (OW) and Lutzomyia in the New World (NW) (Akhoundi et al., 2016).

When a female sand fly takes a blood meal, it provokes skin damage that activates the hemostatic system (Ribeiro and Francischetti, 2003). Sand flies counteract host hemostasis system by injecting 
bioactive salivary components. These bioactive entities include potent vasodilators, e.g., maxadilan in Lutzomiya longipalpis (Lu. longipalpis), and adenosine in Phlebotomus papatasi (P. papatasi) sand flies (Lerner et al., 1991; Ribeiro et al., 1999), apyrases that inhibit platelet aggregation (Valenzuela et al., 2001; Anderson et al., 2006; Hamasaki et al., 2009), and inhibitors of the complement and coagulation cascades, e.g., lufaxin, a Factor Xa inhibitor, in Lu. longipalpis (Charlab et al., 1999; Collin et al., 2009; Abdeladhim et al., 2014). These agents are injected within small amounts of saliva to facilitate bloodfeeding. The sand fly salivary proteome is composed of about 30 secreted proteins (Gomes and Oliveira, 2012) with quite diverse biological activities. Importantly, humans are constantly exposed to sand fly bites in disease endemic areas. Consequently, vector bites also have long-lasting systemic implications once sandfly salivary proteins become immunogenic.

Systemic immune responses to vector saliva are well documented. Brummer-Korvenkontio et al. reported antibody responses (IgG, IgG1, IgM, and $\operatorname{IgE}$ ) to mosquito saliva in the NW (Brummer-Korvenkontio et al., 1994). Similarly, sera from children of endemic areas of Visceral Leishmaniasis (VL) and adults experimentally subjected to $L$ u. longipalpis bites recognized $L u$. longipalpis salivary gland sonicate (SGS) with involvement of IgG (IgG1, and IgG4) and IgE antibodies (Gomes et al., 2002; Vinhas et al., 2007). Marzouki et al. reported the same IgG and IgE anti-SGS responses for the saliva of $P$. papatasi sand flies in endemic areas of Cutaneous Leishmaniasis (CL) (Marzouki et al., 2011). Importantly, cellular responses to sandfly saliva (particularly of pro-inflammatory nature, including IFN- $\gamma$ recall responses) were equally detected in individuals preexposed to vector bites (Vinhas et al., 2007; Oliveira et al., 2013). Of note, at least until midlife, these individuals respond significantly to sand fly bites, which suggests lack of tolerization (Oliveira et al., 2013).

Sand fly salivary proteins may also act as environmental triggers of autoimmune diseases. A link between salivary proteins and autoimmunity is suggested by autoimmune blistering diseases, especially in endemic forms of pemphigus foliaceus (PF) (Diaz et al., 1989; Aoki et al., 2004). Pemphigus are organ-specific autoimmune skin diseases characterized by loss of epidermal adhesion (acantholysis) and blister formation (Lever, 1953; Amagai and Stanley, 2012). Endemic PF, also known as Fogo Selvagem (FS) shares with the sporadic nonendemic form of PF clinical features and pathogenic IgG4 autoantibodies (Rock et al., 1989) directed against the ectodomains of desmoglein 1 (Dsg1) (Amagai and Stanley, 2012). The IgG4 anti-Dsg1 autoantibody response is restricted to FS patients (Warren et al., 2003; Qaqish et al., 2009), whereas the non-pathogenic anti-Dsg1 IgG1 antibodies are detected in disease-free inhabitants of Brazilian endemic populations in the Limao Verde (LV) Amerindian reservation (Warren et al., 2000; Warren et al., 2003; Qaqish et al., 2009). Interestingly, nonpathogenic anti-Dsg1 antibodies are also detected in the sera of patients with Leishmaniasis and Chagas disease (Diaz et al., 2004). An isotype switch from IgG1 to IgG4 pathogenic antiDsg1 response may occur by the epitope spreading mechanism in individuals with the appropriate genetic HLA trait (Li et al., 2003). Notably, IgE and IgG4 anti-Dsg1 autoantibodies in FS patients cross-react with sand fly salivary proteins, likely because of antigenic mimicry (Qian et al., 2015; Qian et al., 2016; Diaz et al., 2020).

Although authors have systematized the knowledge derived from sand fly salivary proteins as disease-controlling agents (Rohousova and Volf, 2006; Andrade and Teixeira, 2012; Abdeladhim et al., 2014; Kamhawi et al., 2014), thus far, no review has included discussion of the participation of some of the sand fly salivary proteins as potential triggers of autoimmune disease. In this Mini Review, we offer an updated overview of sand fly salivary proteins in the context of human disease. The good news is that some proteins are markers of exposure and potential anti-Leishmania vaccines. The bad news is that some proteins may elicit autoimmunity.

\section{MARKERS OF EXPOSURE: SAND FLY SALIVARY PROTEINS AS TOOLS FOR THE CONTROL OF LEISHMANIASIS}

The genomes of humans are remarkably alike; it is estimated that, at the DNA level, any two individuals share 99.9\% identity (Collins and Mansoura, 2001). However, the $0.1 \%$ disparity is enough to condition significant inter-individual variances, including differences in immune responses (Kim-Hellmuth et al., 2017). Indeed, the composition and function of the human immune system are highly variable between healthy individuals, a consequence of heritable and non-heritable factors (Brodin and Davis, 2017). Therefore, it is not surprising that antibody responses vary immensely among humans, including responses to vaccination (Zimmermann and Curtis, 2019). Immunological diversity becomes quite relevant when we consider establishment of "markers of exposure" - essential tools for the determination of exposure to vector bites. Individuals exposed to vector bites show different patterns of antibody binding to salivary proteins (Gomes et al., 2002; Vinhas et al., 2007; Armiyanti et al., 2016). Some salivary proteins are recognized only by the sera of a few individuals. Other proteins are recognized by most sera, which makes these proteins near-universal markers of exposure. Importantly, such markers were proposed as strong indicators of the development of different VBDs (e.g., malaria and Lyme disease), and are important epidemiological risk-assessment tools (Schwartz et al., 1991; Remoue et al., 2006).

Sand flies are widely distributed; in the OW and NW, the genera Phlebotomus and Lutzomyia are responsible, respectively, for the transmission of Leishmania parasites (Akhoundi et al., 2016). In these regions there is an overlap of the (muco)cutaneous and visceral forms of Leishmaniasis, usually associated with different sandfly vectors, with significant disease burden (Akhoundi et al., 2016). Therefore, the development of markers that distinguish individuals exposed to different sand fly vectors is quite important from the epidemiological standpoint.

In the NW, particularly in Brazil, Lu. intermedia, and $\mathrm{Lu}$. longipalpis, are the vectors for cutaneous and visceral 
Leishmaniasis, respectively (Bezerra et al., 2018). Two studies focused on this dichotomy in the search for markers of exposure. Teixeira et al. mined the salivary proteome of $L u$. longipalpis in the quest for specific markers of exposure in the context of different hosts, including humans and dogs (Teixeira et al., 2010). Conversely, Carvalho et al. sought markers of exposure, particularly in humans, among the salivary proteome of $L u$. intermedia (Carvalho et al., 2017). Teixeira et al. proposed LJM17, LJM11, and LJM111 (all yellow-related proteins; 45, 43, and $43 \mathrm{kDa}$, respectively) as potential markers of exposure to $L u$. Longipalpis sand flies (Teixeira et al., 2010), whereas Carvalho et al. suggested LinB-13 (antigen 5-related protein; $28.4 \mathrm{kDa}$ ) as a potential marker of exposure to $\mathrm{Lu}$. intermedia sand flies (Carvalho et al., 2017). LinB-13 was also deemed a potentially good disease biomarker (Carvalho et al., 2017). Of note, there was no cross-reactivity, which suggested that these proteins discriminate individuals exposed to each of these sand fly species, either alone, or in combination (LJM-17 + LJM-11), for better performance as markers (Souza et al., 2010; Teixeira et al., 2010; Carvalho et al., 2017).

In the OW a similar overlap is observed. $P$. papatasi sand flies, the main vectors of cutaneous Leishmaniasis are widely distributed around the Mediterranean basin, North Africa, throughout the Middle East and across the entire Indian subcontinent. In some foci, $P$. papatasi co-exists with $P$. perniciosus and $P$. orientalis sand flies, vectors of the causative agents of visceral Leishmaniasis, Leishmania infantum and Leishmania donovani, respectively (Akhoundi et al., 2016). Different studies have focused on the development of markers of exposure to help navigate such a complex epidemiological situation. In the context of CL, PpSP32, a silkrelated protein was identified as the best marker of human exposure to the bites of $P$. papatasi sand flies. Cross-reactivity with salivary antigens from other co-endemic sand fly species was minimal, as demonstrated using the sera of dogs and humans exposed to $P$. perniciosus and $P$. sergenti, respectively (Marzouki et al., 2012; Marzouki et al., 2015; Mondragon-Shem et al., 2015). Importantly, a biomarker of exposure for dogs to the bites of $P$. perniciosus sand flies was also developed. PpeSP03B, a yellowrelated protein was validated for the screening of dogs in foci of visceral Leishmaniasis caused by $L$. infantum parasites (Drahota et al., 2014; Kostalova et al., 2015; Kostalova et al., 2017; Willen et al., 2018; Willen et al., 2019). Additionally, two P. orientalis salivary proteins were identified as markers of exposure in humans - mAG5 (antigen 5-related protein) and mYEL1 (yellow-related protein) regarding visceral Leishmaniasis caused by $L$. donovani parasites (Sumova et al., 2018). Sima et al. proposed the same yellow-related protein (PorSP24 $=$ mYEL1) as a suitable marker of exposure of domestic animals to the bites of $P$. orientalis sand flies (Sima et al., 2016).

\section{SAND FLY SALIVARY PROTEINS AS ANTI- LEISHMANIA VACCINES}

Sand fly saliva exacerbates the development of Leishmaniasis (Drahota et al., 2014; Marzouki et al., 2015; Mondragon-Shem et al., 2015; Kostalova et al., 2017). This aggravating effect is due to a combination of factors such as the bioactivity of the sand fly salivary proteins. Apart from preventing hemostasis, sand fly saliva/salivary proteins are immunomodulators. As reviewed elsewhere, sand fly salivary components can promote the generation of an antiinflammatory milieu via different mechanisms. This antiinflammatory condition is favorable for the persistence of Leishmania, and it modulates/impacts the recruitment/function of phagocytes essential for the survival of Leishmania in the host phagolysosome compartment (Collin et al., 2009; Abdeladhim et al., 2014). Therefore, immunization approaches based on sand fly salivary proteins have the potential to promote antibodymediated inactivation of sand fly immunomodulatory components, thereby inhibiting establishment of infection. This immunization approach is exactly what was described in the context of two $\mathrm{Lu}$. longipalpis salivary proteins, the hyaluronidase LuloHya (Charlab et al., 1999) and the endonuclease LJL138 (best known as Lundep) (Valenzuela et al., 2004). Immunization with each of these two proteins led to decreased pathology and parasite burden in mice infected with $L$. major parasites together with sandfly saliva; importantly, this phenotype was dependent of antibody responses because it was not observed in B-cell-deficient mice (Martin-Martin et al., 2018). Of note, Chagas et al. reported disease exacerbation mediated by LJL138 (Chagas et al., 2014), which suggested that the protective phenotype was a result of antibody-mediated protein inactivation (Martin-Martin et al., 2018). The same antibody-mediated blockage of activity can also explain the protection obtained against $L$. major infection in animals immunized with the $\mathrm{Lu}$. longipalpis salivary protein LJL08 (maxadilan), although not exclusively because Th1 CD4+ T-cell-mediated responses seem also to have a function (Morris et al., 2001; Wheat et al., 2017). Still in this category, the blockage of the neutrophil chemoattractant activity of the yellow-related proteins PduM10 and PduM35 (Kato et al., 2006) also prevented the exacerbation effect of the saliva of Phlebotomus duboscqi sand flies in the context of a mouse model $L$. major infection (Guimaraes-Costa et al., 2021).

The antibody-mediated blockage of salivary protein activity may explain that naive individuals, not previously exposed to sand fly bites or Leishmania parasites, display a higher risk of developing severe clinical forms of Leishmaniasis than non-naïve persons (Andrade et al., 2007). However, cell-mediated responses are probably the main contributors to such an epidemiological observation. Kamhawi et al. were first to show that pre-exposure to bites from noninfected sand flies induce protection against CL. This finding highlighted the crucial function of CD4+ T cell-dependent Th1 delayed-type hypersensitivity (DTH) responses (Kamhawi et al., 2000), which shaped the field of sand fly saliva-based anti-Leishmania vaccines. In most cases in which sand fly salivary proteins were proposed as anti-Leishmania vaccines, the choice was based on their potential to elicit DTH responses. Different animals were either pre-exposed to sand fly saliva followed by challenge with individual sandfly salivary proteins (via DNA vaccination) (Collin et al., 2009; Oliveira et al., 2015), or pre-immunized with DNA encoding individual sandfly salivary proteins and 
then challenged with sandfly saliva (Gomes et al., 2008; Oliveira et al., 2008; Xu et al., 2011; de Moura et al., 2013; Gholami et al., 2019). Only the proteins that induced significant DTH responses $48 \mathrm{~h}$ after challenge were deemed as potential vaccine candidates worthy of pre-clinical evaluation. This approach consistently led to the discovery of vaccines effective against different forms of Leishmaniasis in the context of vector transmission.

From the saliva of Lu. longipalpis, LJM-19 protected hamsters from fatal VL caused by L. infantum (Gomes et al., 2008) as well as in the context of cutaneous disease caused by Leishmania braziliensis (Tavares et al., 2011). The LJM-11 protein (from Lu.longipalpis) attenuated CL caused by L. major (and $L$. braziliensis) in mice (Xu et al., 2011) (Abi Abdallah et al., 2014; Cunha et al., 2018), as did LJL-14 (Cecilio et al., 2020). Notably, LJL-143 and LJM-17 were proposed as good vaccine candidates against canine Leishmaniasis caused by L. infantum, although an in vivo protective phenotype is yet to be demonstrated (Collin et al., 2009; Abbehusen et al., 2018). Additionally, from the saliva of the closely related $P$. duboscqui and $P$. papatasi sand flies, the homologous salivary proteins PpSP15 and PdSP15 (also known as PduM02) protected mice and non-human primates effectively from $L$. major-induced CL (Oliveira et al., 2008; Oliveira et al., 2015; Davarpanah et al., 2020). Three other proteins from the saliva of $P$. papatasi, PpSP36 (apyrase), PpSP42, and PpSP44 (both yellow-related proteins) were also proposed as good vaccine candidates for human CL (Tlili et al., 2018); however, efficacy results are either still missing, or contrary to this hypothesis in the case of PpSP44 in mice (Oliveira et al., 2008). Interestingly, another protein of the SP15 family, PsSP9 from the saliva of P. sergenti sand flies also protected mice from the development of CL caused by $L$. tropica (Gholami et al., 2019). Finally, from the saliva of $L u$. intermedia, LinB-11 (SP13 family) conferred protection against cutaneous disease in a mouse model of L. braziliensis infection (de Moura et al., 2013). It is important to state that protection in the context of the aforesaid sand fly salivary antigens was associated with dominant pro-inflammatory (e.g. interferon- $\gamma$, and IL-12)/low anti-inflammatory (e.g. IL-4, IL-10, TGF-) CD4+ $\mathrm{T}$ cell-induced cytokine responses (Valenzuela et al., 2001; Gomes et al., 2008; Oliveira et al., 2008; Collin et al., 2009; Tavares et al., 2011; Xu et al., 2011; de Moura et al., 2013; Abi Abdallah et al., 2014; Oliveira et al., 2015; Abbehusen et al., 2018; Cunha et al., 2018; Tlili et al., 2018; Gholami et al., 2019; Cecilio et al., 2020; Davarpanah et al., 2020).

Detailed information of what is known and what is still missing on immune responses to sand fly salivary proteins including in the context of anti-Leishmania vaccines can be found in a few comprehensive reviews (Rohousova and Volf, 2006; Gomes and Oliveira, 2012). Of note, although these vectorderived antigens are effective individually as anti-Leishmania vaccines, their combination with Leishmania-derived antigens in several studies resulted in even more promising vaccine candidates (Zahedifard et al., 2014; Fiuza et al., 2016; Cecilio et al., 2017; Duthie et al., 2017; Fernandez et al., 2021). Considering that the natural infection caused by Leishmania is enhanced by some sand fly salivary proteins, the protective immune response would benefit from the combination of antiLeishmania and anti-sand fly saliva responses.

\section{THE OTHER FACE OF THE COIN: SANDFLY SALIVARY PROTEINS AND AUTOIMMUNITY}

Sand fly saliva is composed of a panoply of proteins with diverse functions. Some of these proteins are vaccine candidates or markers of disease exposure, whereas others can be pleiotropic and identified in both categories. Nevertheless, some markers of disease exposure are also identified as triggers of human autoimmunity, as observed in Fogo Selvagem, a blistering disease that targets Dsg1. Many studies on the etiology of FS were conducted in the Terena reservation of $L V, \sim 1,600$ individuals and a $3 \%$ prevalence for FS (Hans-Filho et al., 1996). FS patients produce IgG, IgM and IgE autoantibodies directed against Dsg1. IgG4 and IgG1 are the main IgG isotypes (Rock et al., 1989; Warren et al., 2003); IgG4 is pathogenic, as demonstrated in passive transfer mouse models (Rock et al., 1989; Evangelista et al., 2018) and the serum titers of IgG4 in patients correlate with disease activity (Warren et al., 2003; Li et al., 2003). In endemic areas, anti-Dsg1 IgG4 has a positive predictive value of $50 \%$ in identifying inhabitants with preclinical stages of FS (Qaqish et al., 2009). The IgG4 anti-Dsg1restricted disease is strongly associated with $\mathrm{HLADRB} 1^{\star} 0102$, 0404 and 1402 alleles, conferring a relative risk of 14 (Moraes et al., 1997).

Some rural populations in Brazil chronically exposed to insect bites, such as blackflies and reduviid (vector of Chagas disease) exhibit an autoantibody response against Dsg1 (Diaz et al., 2004).Interestingly, approximately $50 \%$ of the normal population possess nonpathogenic anti-Dsg1 autoantibodies (Warren et al., 2000; Qaqish et al., 2009). Epidemiological studies on the LV reservation strongly suggest that bloodfeeding insects are risk factors for FS (Eaton et al., 1998; Aoki et al., 2004). Healthy individuals living in endemic areas of FS have higher frequency of IgM autoantibodies, compared with individuals from nonendemic FS regions, such as Japan and US. These IgM autoantibodies, although absent from the cord sera of mothers from LV (Hilario-Vargas et al., 2014), can be detected as early as five year of age (Diaz et al., 2008); the autoantibodies decrease as the inhabitants depart from endemic areas to urban sites, which suggests the influence of an environmental factor in autoantibody production (Diaz et al., 2008). Moreover, antigen selection is antigen driven even in pre-clinical stages, as demonstrated by our analysis of $\mathrm{H}$ and $\mathrm{L}$ chains of $\mathrm{V}$ genes of anti-Dsg1 IgM, reinforcing the idea of environmental triggers (Qian et al., 2009).

Recent advances in the characterization of Dsg1 epitopes show that $95 \%$ of IgG4 antibodies of FS sera recognize a 16-residue peptide $\left(\mathrm{A}_{129} \mathrm{LNSMGQDLERPLELR}_{144}\right)$ located in the extracellular domain 1 of Dsg1 (Evangelista et al., 2018). This sequence overlaps the arginine-alanine-leucine (RAL) adhesive 
site of Dsg1, into which tryptophan residue 2 (Trp2) of desmocollin 1 (Dsc1) is inserted to bring desmosomal adhesion. The antigen-binding site of the FS IgG4 autoantibody binds a conformational epitope in the Dsg1 pocket. Mutation of M133, Q135, Q82 and V83 residues of the Dsg1 pocket abolish binding of FS IgG4 autoantibodies. Additionally, the Fab fragments of FS IgG4 autoantibodies inhibit the heterophilic aggregation of Dsg1/ Dsc1 in a dose dependent manner (Evangelista et al., 2018). These studies strongly suggest that pathogenic FS IgG4 autoantibodies induce cell detachment and blisters in the epidermis by inhibiting the interaction of Dsg1 and Dsc1 desmosomal cadherins of FS patients. Steric hindrance and/or intracellular signaling or apoptosis are possible mechanisms under investigation.

In Brazil, FS endemic sites overlap with areas of high prevalence of VBDs, especially Leishmaniasis (Diaz et al., 1989). Circulating anti-Dsg1 autoantibodies are detected in patients with insect-borne diseases such as Leishmaniasis and Chagas disease (Diaz et al., 2004; Walsh et al., 2017) and also in dogs and cats (Ginel et al., 1993). We then hypothesized that chronic exposure to insect bites and the salivary antigens therein could be a relevant trigger to FS. To understand whether the chronic exposure to insect bites (or insect salivary antigens) is a relevant trigger to FS, we collected serum samples from FS patients and investigated their reactivity toward $\mathrm{Lu}$. longipalpis SGH (Valenzuela et al., 2004; Xu et al., 2011; Abdeladhim et al., 2014). We found significant correlation between levels of IgG4 and anti-IgE antibodies directed against Lu. longipalpis LJM 17 and 11 with anti-Dsg1 autoantibodies due to possible crossreactivity (Qian et al., 2012; Qian et al., 2015). Further studies showed that sera from healthy controls and FS patients from endemic sites exhibited significant higher levels of IgG4 antiLJM17 antibodies compared to nonendemic controls. Moreover,
A

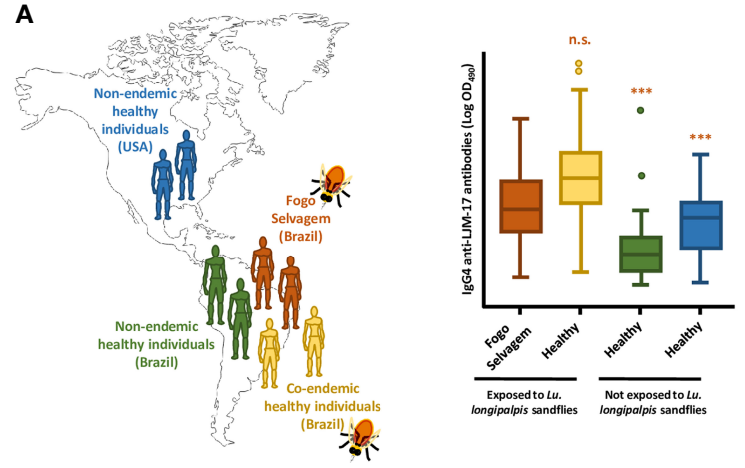

B
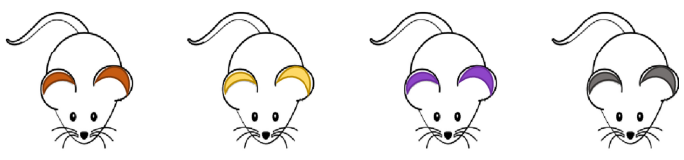

rபM17

rUM11

saline
(naive)

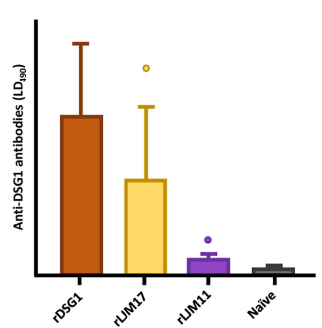

FIGURE 1 | The potential association between the exposure to sandfly bites and the development of Fogo Selvagem (FS), in Limao Verde, Brazil. (A) In endemic areas of FS in Brazil, patients (Fogo Selvagem, orange) and healthy controls who are chronically exposed to the bites of Lu. longipalpis sandflies (Co-endemic healthy individuals, yellow) produce high and comparable levels of IgG4 antibodies against the sand fly salivary protein LJM17. This humoral immune response is not observed in normal individuals living in non-endemic areas, both in Brazil (Non-endemic healthy individuals, green), and in the USA (Non-endemic healthy individuals, blue). The relative levels of IGg4 antibodies anti- LJM17, are shown in the form of box-and-whiskers plots. (B) Mice immunized with recombinant LJM17 developed IgG1 antibodies (murine homologue of human lgG4) that cross-reacted with recombinant human Dsg1 (yellow). Mice in the positive and negative control groups, immunized with rDsg1 (orange) and saline (blue), respectively, showed the expected antibody responses against recombinant human Dsg1 (high, and very low, respectively. Additionally, mice immunized with LJM11 (purple) generated low titers of anti-Dsg1 antibodies. The levels of anti- Dsg1 antibodies are shown in the form bar graphs. This Figure is an adaptation of the data published by Diaz et al. (2020). ${ }^{\star \star \star}(\mathrm{p}<0.001)$, n.s., normal human sera. 
IgG anti-Dsg1 and IgG4 anti-LJM17 and anti-LJM11 antibodies positively correlated in normal settlers and FS patients (Diaz et al., 2020) (Figure 1A). Mice immunized with recombinant LJM17 developed nonpathogenic IgG1 antibodies (murine homologous of human IgG4) that cross-reacted with recombinant human Dsg1 (Figure 1B). We also identified short-sequence homologies of surface-exposed residues within the human DSG1 ectodomain and LJM17 (Diaz et al., 2020).

In the OW, Tunisians with endemic PF (Bastuji-Garin et al., 1995; Zaraa et al., 2012) have an increased IgG4 antibody response to $P$. papatasi salivary proteins, particularly SP32 (Marzouki et al., 2011; Marzouki et al., 2015; Marzouki et al., 2020). Marzouki et al. showed that PpSP32 bound directly to Dsg1 and Dsg3 forming immunogenic complexes; however, mice immunized with PpSP32 developed non-cross-reactive antibodies that recognized Dsg1 and Dsg3 (Marzouki et al., 2020). Marzouki et al. (2020) suggested that the PpSP32/Dsg1 and PpSP32/Dsg3 complexes induce loss of tolerance to these autoantigens and trigger pemphigus in genetically predisposed individuals.
Altogether, studies in different geographical settings suggest an association between the exposure of pre-disposed individuals to sand fly bites, and the development of autoimmune blistering diseases. The potential cross-reactivity of some sand fly salivary gland proteins (LJM 17 and 11 in the NW and PpSP32 in the OW) with Dsg1, the autoantigen of endemic pemphigus foliaceus, indicates the need for a careful choice when selecting such proteins as candidates for anti-Leishmania vaccines.

\section{CONCLUDING REMARKS}

The birth of transcriptomics and proteomics allowed the detailed analysis of the salivary proteins of different sand fly species, especially in the field of infectious diseases. Some molecules were proposed as markers of exposure in endemic areas of Leishmaniasis, whilst others were defined as promising antiLeishmania vaccine candidates; however, some are potential environmental triggers of autoimmune skin diseases (Figure 2). Table 1 depicts a summary of sand fly salivary

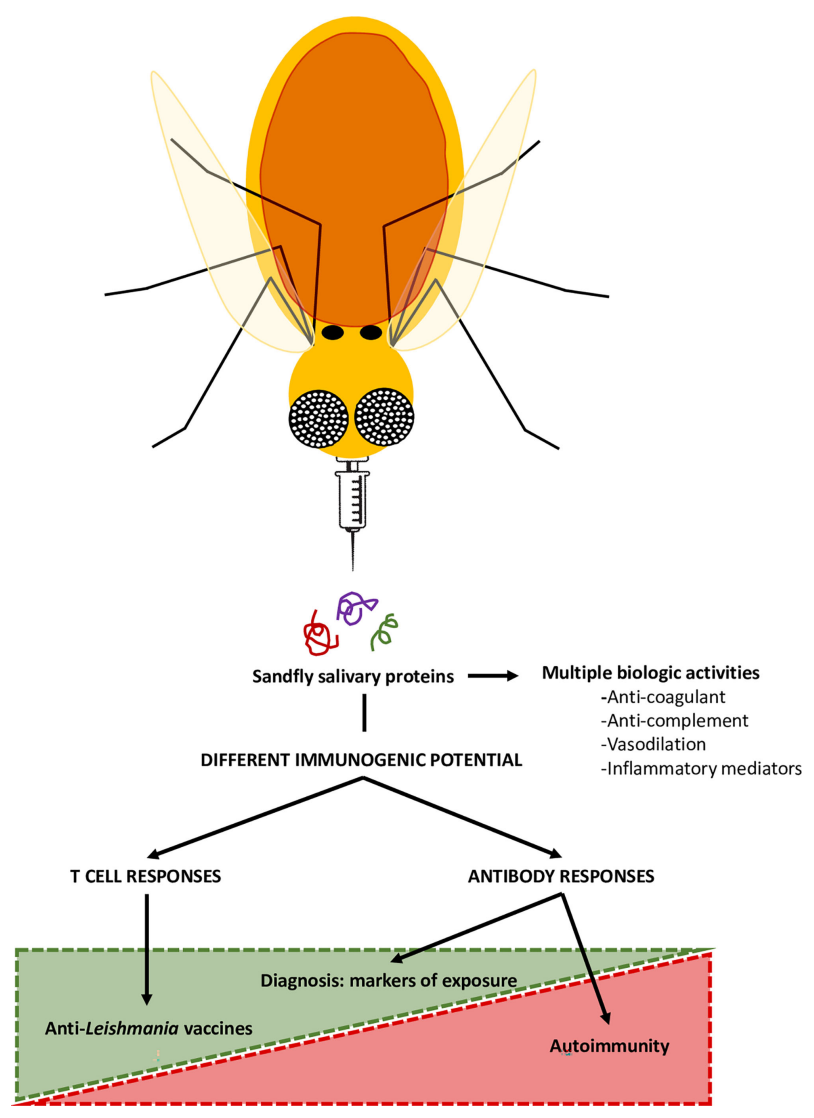

FIGURE 2 | Sand fly salivary proteins in the control of Leishmaniasis and in autoimmunity. The saliva of blood-sucking arthropods, including sandflies, here represented as flying needles, contains components with immunomodulatory and anti-hemostatic properties. However, these proteins are also immunogenic, and, thus able to induce systemic immune responses. Therefore, some proteins may be used as markers of exposure of sandfly bites, with epidemiological value, or as components of anti-Leishmania vaccines. However, certain sand fly salivary proteins can sensitize the host and potentially trigger the formation of cross-reactive antibodies that may lead to the development of autoimmune blistering diseases, such as pemphigus foliaceus. 
TABLE 1 | Sand fly salivary proteins as markers of exposure, anti-Leishmania vaccines, and potential triggers of autoimmunity.

\begin{tabular}{|c|c|c|c|c|c|}
\hline & $\begin{array}{l}\text { Sand fly } \\
\text { species }\end{array}$ & $\begin{array}{l}\text { Salivary } \\
\text { Protein }\end{array}$ & $\begin{array}{l}\text { Salivary } \\
\text { Protein family }\end{array}$ & Species tested & Ref. \\
\hline \multirow[t]{8}{*}{ Markers of exposure } & Lu. longipalpis & LJM11 & $\begin{array}{l}\text { Yellow-related } \\
\text { protein }\end{array}$ & $\begin{array}{l}\text { Humans, dogs, } \\
\text { chicken }\end{array}$ & (Teixeira et al., 2010) \\
\hline & & LJM17 & $\begin{array}{l}\text { Yellow-related } \\
\text { protein }\end{array}$ & $\begin{array}{l}\text { Humans, dogs, } \\
\text { chicken, foxes }\end{array}$ & (Teixeira et al., 2010) \\
\hline & & LJM111 & $\begin{array}{l}\text { Yellow-related } \\
\text { protein }\end{array}$ & Humans & (Teixeira et al., 2010) \\
\hline & Lu. intermedia & Linb-13 & $\begin{array}{l}\text { Antigen-5- } \\
\text { related protein }\end{array}$ & Humans & (Carvalho et al., 2017) \\
\hline & P. papatasi & PpSP32 & $\begin{array}{l}\text { Silk-related } \\
\text { protein }\end{array}$ & Humans & $\begin{array}{l}\text { (Marzouki et al., 2012; Marzouki et al., 2015; Mondragon-Shem } \\
\text { et al., 2015) }\end{array}$ \\
\hline & P. perniciosus & РpeP03B & $\begin{array}{l}\text { Yellow-related } \\
\text { protein }\end{array}$ & Dogs & $\begin{array}{l}\text { (Drahota et al., 2014; Kostalova et al., 2015; Kostalova et al., 2017; } \\
\text { Willen et al., 2018; Willen et al., 2019) }\end{array}$ \\
\hline & P. orientalis & mAG5 & $\begin{array}{l}\text { Antigen-5- } \\
\text { related protein }\end{array}$ & Humans & (Sumova et al., 2018) \\
\hline & & $\begin{array}{l}\text { mYEL1 or } \\
\text { PorSP24 }\end{array}$ & $\begin{array}{l}\text { Yellow-related } \\
\text { protein }\end{array}$ & $\begin{array}{l}\text { Humans, domestic } \\
\text { animals }\end{array}$ & (Sima et al., 2016; Sumova et al., 2018) \\
\hline \multirow{11}{*}{$\begin{array}{l}\text { Anti-Leishmania } \\
\text { vaccines }\end{array}$} & Lu. Longipalpis & LJM-19 & SALO & Hamsters & (Gomes et al., 2008; Tavares et al., 2011) \\
\hline & & LJM11 & $\begin{array}{l}\text { Yellow-related } \\
\text { protein }\end{array}$ & Mice & (Xu et al., 2011; Abi Abdallah et al., 2014; Cunha et al., 2018) \\
\hline & & LJM17 & $\begin{array}{l}\text { Yellow-related } \\
\text { protein }\end{array}$ & Dogs & (Collin et al., 2009; Abbehusen et al., 2018) \\
\hline & & LJL143 & Lufaxin & Dogs & (Collin et al., 2009; Abbehusen et al., 2018) \\
\hline & Lu. Intermedia & Linb-11 & SP13 family & Mice & (de Moura et al., 2013) \\
\hline & P. papatasi & PpSP15 & $\begin{array}{l}\text { OBP-related } \\
\text { protein }\end{array}$ & Mice & (Oliveira et al., 2008; Davarpanah et al., 2020) \\
\hline & & PpSP36 & Apyrase & Humans & (Tlili et al., 2018) \\
\hline & & PpSP42 & $\begin{array}{l}\text { Yellow-related } \\
\text { protein }\end{array}$ & Humans & (Tlili et al., 2018) \\
\hline & & PpSP44 & $\begin{array}{l}\text { Yellow-related } \\
\text { protein }\end{array}$ & Humans & (Tlili et al., 2018) \\
\hline & P. duboscqi & $\begin{array}{l}\text { PdSP15 } \\
\text { (PduM02) }\end{array}$ & $\begin{array}{l}\text { OBP-related } \\
\text { protein }\end{array}$ & $\begin{array}{l}\text { Non-Human } \\
\text { primates }\end{array}$ & (Oliveira et al., 2015) \\
\hline & P. sergenti & PsSP9 & $\begin{array}{l}\text { OBP-related } \\
\text { protein }\end{array}$ & Mice & (Gholami et al., 2019) \\
\hline \multirow[t]{3}{*}{$\begin{array}{l}\text { Potential triggers of } \\
\text { autoimmunity }\end{array}$} & Lu. longipalpis & LJM11 & $\begin{array}{l}\text { Yellow-related } \\
\text { protein }\end{array}$ & / & (Diaz et al., 2020) \\
\hline & & LJM17 & $\begin{array}{l}\text { Yellow-related } \\
\text { protein }\end{array}$ & / & (Diaz et al., 2020) \\
\hline & P. papatasi & PpSP32 & $\begin{array}{l}\text { Silk-related } \\
\text { protein }\end{array}$ & / & (Zaraa et al., 2012) \\
\hline
\end{tabular}

proteins and their potential role as markers of exposure, vaccine components or triggers in autoimmunity. Importantly, this tool or trigger duality must be patent in the development of sand fly saliva based anti-Leishmania vaccines, and only those molecules which are not inducers of autoimmunity responses (auspiciously most of the salivary gland proteins) should be applied for clinical development studies.

\section{ETHICS STATEMENT}

The human studies performed in this investigation were approved by Institutional Review Boards from the University of North Carolina and the University of Sao Paulo.

\section{AUTHOR CONTRIBUTIONS}

All the authors meet all criteria for authorship in the ICMJE recommendations. All authors were involved in the conceptualization, data acquisition, interpretation of data, and writing this minireview. All Authors approved the final submitted version. All the authors agreed to be accountable for all aspects of the work.

\section{FUNDING}

This research was supported in part by RO1 AR32599 and CTSA-UL1TR002489 (LAD) and the Intramural Research Programs at the National Institute of Allergy and Infectious Diseases, National Institutes of Health (JV, MA, PC). 


\section{REFERENCES}

Abbehusen, M. M. C., Cunha, J., Suarez, M. S., Teixeira, C., Almeida, V. D. A., Pereira, L. D. S., et al. (2018). Immunization of Experimental Dogs With Salivary Proteins From Lutzomyia Longipalpis, Using DNA and Recombinant Canarypox Virus Induces Immune Responses Consistent With Protection Against Leishmania Infantum. Front. Immunol. 9. doi: 10.3389/fimmu.2018.02558

Abdeladhim, M., Kamhawi, S., and Valenzuela, J. G. (2014). What's Behind a Sand Fly Bite? The Profound Effect of Sand Fly Saliva on Host Hemostasis, Inflammation and Immunity. Infect. Genet. Evol. 28, 691-703. doi: 10.1016/ j.meegid.2014.07.028

Abi Abdallah, D. S., Pavinski Bitar, A., Oliveira, F., Meneses, C., Park, J. J., Mendez, S., et al. (2014). A Listeria Monocytogenes-Based Vaccine That Secretes Sand Fly Salivary Protein LJM11 Confers Long-Term Protection Against VectorTransmitted Leishmania Major. Infect. Immun. 82 (7), 2736-2745. doi: 10.1128/IAI.01633-14

Akhoundi, M., Kuhls, K., Cannet, A., Votypka, J., Marty, P., Delaunay, P., et al. (2016). A Historical Overview of the Classification, Evolution, and Dispersion of Leishmania Parasites and Sandflies. PloS Negl. Trop. Dis. 10 (3), e0004349. doi: 10.1371/journal.pntd.0004349

Amagai, M., and Stanley, J. R. (2012). Desmoglein as a Target in Skin Disease and Beyond. J. Invest. Dermatol. 132 (3 Pt 2), 776-784. doi: 10.1038/jid.2011.390

Anderson, J. M., Oliveira, F., Kamhawi, S., Mans, B. J., Reynoso, D., Seitz, A. E., et al. (2006). Comparative Salivary Gland Transcriptomics of Sandfly Vectors of Visceral Leishmaniasis. BMC Genomics 7, 52. doi: 10.1186/1471-2164-7-52

Andrade, B. B., de Oliveira, C. I., Brodskyn, C. I., Barral, A., and Barral-Netto, M. (2007). Role of Sand Fly Saliva in Human and Experimental Leishmaniasis: Current Insights. Scand. J. Immunol. 66 (2-3), 122-127. doi: 10.1111/j.13653083.2007.01964.x

Andrade, B. B., and Teixeira, C. R. (2012). Biomarkers for Exposure to Sand Flies Bites as Tools to Aid Control of Leishmaniasis. Front. Immunol. 3. doi: 10.3389/fimmu.2012.00121

Aoki, V., Millikan, R. C., Rivitti, E. A., Hans-Filho, G., Eaton, D. P., Warren, S. J., et al. (2004). Environmental Risk Factors in Endemic Pemphigus Foliaceus (Fogo Selvagem). J. Investig. Dermatol. Symp. Proc. 9 (1), 34-40. doi: 10.1111/ j.1087-0024.2004.00833.x

Armiyanti, Y., Arifianto, R. P., Riana, E. N., Senjarini, K., Widodo, W., Fitri, L. E., et al. (2016). Identification of Antigenic Proteins From Salivary Glands of Female Anopheles Maculatus by Proteomic Analysis. Asian Pac. J. Trop. Bio 6 (11), 924-930. doi: 10.1016/j.apjtb.2016.08.012

Bastuji-Garin, S., Souissi, R., Blum, L., Turki, H., Nouira, R., Jomaa, B., et al. (1995). Comparative Epidemiology of Pemphigus in Tunisia and France: Unusual Incidence of Pemphigus Foliaceus in Young Tunisian Women. J. Invest. Dermatol. 104 (2), 302-305. doi: 10.1111/1523-1747.ep12612836

Bezerra, J. M. T., de Araujo, V. E. M., Barbosa, D. S., Martins-Melo, F. R., Werneck, G. L., and Carneiro, M. (2018). Burden of Leishmaniasis in Brazil and Federated Units, 1990-2016: Findings From Global Burden of Disease Study 2016. PloS Negl. Trop. Dis. 12 (9), e0006697. doi: 10.1371/journal.pntd.0006697

Brodin, P., and Davis, M. M. (2017). Human Immune System Variation. Nat. Rev. Immunol. 17 (1), 21-29. doi: 10.1038/nri.2016.125

Brummer-Korvenkontio, H., Lappalainen, P., Reunala, T., and Palosuo, T. (1994). Detection of Mosquito Saliva-Specific IgE and IgG4 Antibodies by Immunoblotting. J. Allergy Clin. Immunol. 93 (3), 551-555. doi: 10.1016/ s0091-6749(94)70066-4

Carvalho, A. M., Fukutani, K. F., Sharma, R., Curvelo, R. P., Miranda, J. C., Barral, A., et al. (2017). Seroconversion to Lutzomyia Intermedia LinB-13 as a Biomarker for Developing Cutaneous Leishmaniasis. Sci. Rep. 7 (1), 3149. doi: 10.1038/s41598-017-03345-0

Cecilio, P., Perez-Cabezas, B., Fernandez, L., Moreno, J., Carrillo, E., Requena, J. M., et al. (2017). Pre-Clinical Antigenicity Studies of an Innovative Multivalent Vaccine for Human Visceral Leishmaniasis. PloS Negl. Trop. Dis. 11 (11), e0005951. doi: 10.1371/journal.pntd.0005951

Cecilio, P., Pires, A., Valenzuela, J. G., Pimenta, P. F. P., Cordeiro-da-Silva, A., Secundino, N. F. C., et al. (2020). Exploring Lutzomyia Longipalpis Sand Fly Vector Competence for Leishmania Major Parasites. J. Infect. Dis. 222 (7), 1199-1203. doi: 10.1093/infdis/jiaa203

Chagas, A. C., Oliveira, F., Debrabant, A., Valenzuela, J. G., Ribeiro, J. M., and Calvo, E. (2014). Lundep, a Sand Fly Salivary Endonuclease Increases
Leishmania Parasite Survival in Neutrophils and Inhibits XIIa Contact Activation in Human Plasma. PloS Pathog. 10 (2), e1003923. doi: 10.1371/ journal.ppat.1003923

Charlab, R., Valenzuela, J. G., Rowton, E. D., and Ribeiro, J. M. (1999). Toward an Understanding of the Biochemical and Pharmacological Complexity of the Saliva of a Hematophagous Sand Fly Lutzomyia Longipalpis. Proc. Natl. Acad. Sci. U. S. A. 96 (26), 15155-15160. doi: 10.1073/pnas.96.26.15155

Collin, N., Gomes, R., Teixeira, C., Cheng, L., Laughinghouse, A., Ward, J. M., et al. (2009). Sand Fly Salivary Proteins Induce Strong Cellular Immunity in a Natural Reservoir of Visceral Leishmaniasis With Adverse Consequences for Leishmania. PloS Pathog. 5 (5), e1000441. doi: 10.1371/journal.ppat.1000441

Collins, F. S., and Mansoura, M. K. (2001). The Human Genome Project. Revealing the Shared Inheritance of All Humankind. Cancer 91 (1 Suppl), 221-225. doi: 10.1002/1097-0142(20010101)91:1+<221::aid-cncr8>3.3.co;2-0

Cunha, J. M., Abbehusen, M., Suarez, M., Valenzuela, J., Teixeira, C. R., and Brodskyn, C. I. (2018). Immunization With LJM11 Salivary Protein Protects Against Infection With Leishmania Braziliensis in the Presence of Lutzomyia Longipalpis Saliva. Acta Trop. 177, 164-170. doi: 10.1016/.jactatropica.2017.10.009

Davarpanah, E., Seyed, N., Bahrami, F., Rafati, S., Safaralizadeh, R., and Taheri, T. (2020). Lactococcus Lactis Expressing Sand Fly PpSP15 Salivary Protein Confers Long-Term Protection Against Leishmania Major in BALB/c Mice. PloS Negl. Trop. Dis. 14 (1), e0007939. doi: 10.1371/journal.pntd.0007939

de Moura, T. R., Oliveira, F., Carneiro, M. W., Miranda, J. C., Clarencio, J., BarralNetto, M., et al. (2013). Functional Transcriptomics of Wild-Caught Lutzomyia Intermedia Salivary Glands: Identification of a Protective Salivary Protein Against Leishmania Braziliensis Infection. PloS Negl. Trop. Dis. 7 (5), e2242. doi: 10.1371/journal.pntd.0002242

Diaz, L. A., Arteaga, L. A., Hilario-Vargas, J., Valenzuela, J. G., Li, N., Warren, S., et al. (2004). Anti-Desmoglein-1 Antibodies in Onchocerciasis, Leishmaniasis and Chagas Disease Suggest a Possible Etiological Link to Fogo Selvagem. J. Invest. Dermatol. 123 (6), 1045-1051. doi: 10.1111/j.0022-202X.2004.23438.x

Diaz, L. A., Prisayanh, P. S., Dasher, D. A., Li, N., Evangelista, F., Aoki, V., et al. (2008). The IgM Anti-Desmoglein 1 Response Distinguishes Brazilian Pemphigus Foliaceus (Fogo Selvagem) From Other Forms of Pemphigus. J. Invest. Dermatol. 128 (3), 667-675. doi: 10.1038/sj.jid.5701121

Diaz, L. A., Prisayanh, P., Qaqish, B., Temple, B. R., Aoki, V., Hans-Filho, G., et al. (2020). Cooperative Group of Fogo Selvagem R. A Lutzomyia Longipalpis Salivary Protein Induces Cross-Reactive Antibodies to Pemphigus Autoantigen Desmoglein 1. J. Invest. Dermatol. 140 (12), 2332-2342.e10. doi: 10.1016/ j.jid.2020.02.041

Diaz, L. A., Sampaio, S. A., Rivitti, E. A., Martins, C. R., Cunha, P. R., Lombardi, C., et al. (1989). Endemic Pemphigus Foliaceus (Fogo Selvagem): II. Current and Historic Epidemiologic Studies. J. Invest. Dermatol. 92 (1), 4-12. doi: 10.1111/ 1523-1747.ep13070394. Cited in: Pubmed

Drahota, J., Martin-Martin, I., Sumova, P., Rohousova, I., Jimenez, M., Molina, R., et al. (2014). Recombinant Antigens From Phlebotomus Perniciosus Saliva as Markers of Canine Exposure to Visceral Leishmaniases Vector. PloS Negl. Trop. Dis. 8 (1), e2597. doi: 10.1371/journal.pntd.0002597

Duthie, M. S., Pereira, L., Favila, M., Hofmeyer, K. A., Reed, S. J., Metangmo, S., et al. (2017). A Defined Subunit Vaccine That Protects Against Vector-Borne Visceral Leishmaniasis. NPJ Vaccines 2, 23. doi: 10.1038/s41541-017-0025-5.

Eaton, D. P., Diaz, L. A., Hans-Filho, G., Santos, V. D., Aoki, V., Friedman, H., et al. (1998). Comparison of Black Fly Species (Diptera: Simuliidae) on an Amerindian Reservation With a High Prevalence of Fogo Selvagem to Neighboring Disease-Free Sites in the State of Mato Grosso do Sul, Brazil. The Cooperative Group on Fogo Selvagem Research. J. Med. Entomol. 35 (2), 120-131. doi: 10.1093/jmedent/35.2.120

Evangelista, F., Roth, A. J., Prisayanh, P., Temple, B. R., Li, N., Qian, Y., et al. (2018). Pathogenic IgG4 Autoantibodies From Endemic Pemphigus Foliaceus Recognize a Desmoglein-1 Conformational Epitope. J. Autoimmun. 89, 171185. doi: 10.1016/j.jaut.2017.12.017

Fernandez, L., Solana, J. C., Sanchez, C., Jimenez, M. A., Requena, J. M., Coler, R., et al. (2021). Protective Efficacy in a Hamster Model of a Multivalent Vaccine for Human Visceral Leishmaniasis (MuLeVaClin) Consisting of the KMP11, LEISH-F3+, and LJL143 Antigens in Virosomes, Plus GLA-SE Adjuvant. Microorganisms 9 (11), 2253. doi: 10.3390/microorganisms9112253

Fiuza, J. A., Dey, R., Davenport, D., Abdeladhim, M., Meneses, C., Oliveira, F., et al. (2016). Intradermal Immunization of Leishmania Donovani Centrin 
Knock-Out Parasites in Combination With Salivary Protein LJM19 From Sand Fly Vector Induces a Durable Protective Immune Response in Hamsters. PloS Negl. Trop. Dis. 10 (1), e0004322. doi: 10.1371/journal.pntd.0004322

Gholami, E., Oliveira, F., Taheri, T., Seyed, N., Gharibzadeh, S., Gholami, N., et al. (2019). DNA Plasmid Coding for Phlebotomus Sergenti Salivary Protein PsSP9, a Member of the SP15 Family of Proteins, Protects Against Leishmania Tropica. PloS Negl. Trop. Dis. 13 (1), e0007067. doi: 10.1371/ journal.pntd.0007067

Ginel, P. J., Mozos, E., Fernandez, A., Martinez, A., and Molleda, J. M. (1993). Canine Pemphigus Foliaceus Associated With Leishmaniasis. Vet. Rec. 133 (21), 526-527. doi: 10.1136/vr.133.21.526

Gomes, R. B., Brodskyn, C., de Oliveira, C. I., Costa, J., Miranda, J. C., Caldas, A., et al. (2002). Seroconversion Against Lutzomyia Longipalpis Saliva Concurrent With the Development of Anti-Leishmania Chagasi Delayed-Type Hypersensitivity. J. Infect. Dis. 186 (10), 1530-1534. doi: 10.1086/344733

Gomes, R., and Oliveira, F. (2012). The Immune Response to Sand Fly Salivary Proteins and Its Influence on Leishmania Immunity. Front. Immunol. 3. doi: 10.3389 /fimmu.2012.00110

Gomes, R., Teixeira, C., Teixeira, M. J., Oliveira, F., Menezes, M. J., Silva, C., et al. (2008). Immunity to a Salivary Protein of a Sand Fly Vector Protects Against the Fatal Outcome of Visceral Leishmaniasis in a Hamster Model. Proc. Natl. Acad. Sci. U. S. A. 105 (22), 7845-7850. doi: 10.1073/pnas.0712153105

Guimaraes-Costa, A. B., Shannon, J. P., Waclawiak, I., Oliveira, J., Meneses, C., de Castro, W., et al. (2021). A Sand Fly Salivary Protein Acts as a Neutrophil Chemoattractant. Nat. Commun. 12 (1), 3213. doi: 10.1038/s41467-021-23002-5

Hamasaki, R., Kato, H., Terayama, Y., Iwata, H., and Valenzuela, J. G. (2009). Functional Characterization of a Salivary Apyrase From the Sand Fly, Phlebotomus Duboscqi, a Vector of Leishmania Major. J. Insect Physiol. 55 (11), 1044-1049. doi: 10.1016/j.jinsphys.2009.07.010

Hans-Filho, G., dos Santos, V., Katayama, J. H., Aoki, V., Rivitti, E. A., Sampaio, S. A., et al. (1996). An Active Focus of High Prevalence of Fogo Selvagem on an Amerindian Reservation in Brazil. Cooperative Group on Fogo Selvagem Research. J. Invest. Dermatol. 107 (1), 68-75. doi: 10.1111/1523-1747. ep12298213

Hilario-Vargas, J., Vitorio, I. B., Stamey, C., Culton, D. A., Prisayanh, P., Rivitti, E. A., et al. (2014). Analysis of Anti-Desmoglein 1 Autoantibodies in 68 Healthy Mother/Neonate Pairs From a Highly Endemic Region of Fogo Selvagem in Brazil. J. Clin. Exp. Dermatol. Res. 5 (2). doi: 10.4172/2155-9554.1000209

Kamhawi, S., Aslan, H., and Valenzuela, J. G. (2014). Vector Saliva in Vaccines for Visceral Leishmaniasis: A Brief Encounter of High Consequence? Front. Public Health 2. doi: 10.3389/fpubh.2014.00099

Kamhawi, S., Belkaid, Y., Modi, G., Rowton, E., and Sacks, D. (2000). Protection Against Cutaneous Leishmaniasis Resulting From Bites of Uninfected Sand Flies. Science 290 (5495), 1351-1354. doi: 10.1126/science.290.5495.1351

Kato, H., Anderson, J. M., Kamhawi, S., Oliveira, F., Lawyer, P. G., Pham, V. M., et al. (2006). High Degree of Conservancy Among Secreted Salivary Gland Proteins From Two Geographically Distant Phlebotomus Duboscqi Sandflies Populations (Mali and Kenya). BMC Genomics 7, 226. doi: 10.1186/1471-2164-7-226

Kim-Hellmuth, S., Bechheim, M., Putz, B., Mohammadi, P., Nedelec, Y., Giangreco, N., et al. (2017). Genetic Regulatory Effects Modified by Immune Activation Contribute to Autoimmune Disease Associations. Nat. Commun. 8 (1), 266. doi: 10.1038/s41467-017-00366-1

Kostalova, T., Lestinova, T., Maia, C., Sumova, P., Vlkova, M., Willen, L., et al. (2017). The Recombinant Protein Rsp03b Is a Valid Antigen for Screening Dog Exposure to Phlebotomus Perniciosus Across Foci of Canine Leishmaniasis. Med. Vet. Entomol. 31 (1), 88-93. doi: 10.1111/mve.12192

Kostalova, T., Lestinova, T., Sumova, P., Vlkova, M., Rohousova, I., Berriatua, E., et al. (2015). Canine Antibodies Against Salivary Recombinant Proteins of Phlebotomus Perniciosus: A Longitudinal Study in an Endemic Focus of Canine Leishmaniasis. PloS Negl. Trop. Dis. 9 (6), e0003855. doi: 10.1371/ journal.pntd.0003855

Lerner, E. A., Ribeiro, J. M., Nelson, R. J., and Lerner, M. R. (1991). Isolation of Maxadilan, a Potent Vasodilatory Peptide From the Salivary Glands of the Sand Fly Lutzomyia Longipalpis. J. Biol. Chem. 266 (17), 11234-11236. doi: 10.1016/S0021-9258(18)99153-2

Lever, W. F. (1953). Pemphigus. Med. (Baltimore) 32 (1), 1-123. doi: 10.1097/ 00005792-195302000-00001
Li, N., Aoki, V., Hans-Filho, G., Rivitti, E. A., and Diaz, L. A. (2003). The Role of Intramolecular Epitope Spreading in the Pathogenesis of Endemic Pemphigus Foliaceus (Fogo Selvagem). J. Exp. Med. 197 (11), 1501-1510. doi: 10.1084/ jem. 20022031

Martin-Martin, I., Chagas, A. C., Guimaraes-Costa, A. B., Amo, L., Oliveira, F., Moore, I. N., et al. (2018). Immunity to LuloHya and Lundep, the Salivary Spreading Factors From Lutzomyia Longipalpis, Protects Against Leishmania Major Infection. PloS Pathog. 14 (5), e1007006. doi: 10.1371/journal.ppat.1007006

Marzouki, S., Abdeladhim, M., Abdessalem, C. B., Oliveira, F., Ferjani, B., Gilmore, D., et al. (2012). Salivary Antigen SP32 Is the Immunodominant Target of the Antibody Response to Phlebotomus Papatasi Bites in Humans. PloS Negl. Trop. Dis. 6 (11), e1911. doi: 10.1371/journal.pntd.0001911

Marzouki, S., Ben Ahmed, M., Boussoffara, T., Abdeladhim, M., Ben AleyaBouafif, N., Namane, A., et al. (2011). Characterization of the Antibody Response to the Saliva of Phlebotomus Papatasi in People Living in Endemic Areas of Cutaneous Leishmaniasis. Am. J. Trop. Med. Hyg. 84 (5), 653-661. doi: 10.4269/ajtmh.2011.10-0598

Marzouki, S., Kammoun-Rebai, W., Bettaieb, J., Abdeladhim, M., Hadj Kacem, S., Abdelkader, R., et al. (2015). Validation of Recombinant Salivary Protein PpSP32 as a Suitable Marker of Human Exposure to Phlebotomus Papatasi, the Vector of Leishmania Major in Tunisia. PloS Negl. Trop. Dis. 9 (9), e0003991. doi: 10.1371/journal.pntd.0003991

Marzouki, S., Zaraa, I., Abdeladhim, M., Benabdesselem, C., Oliveira, F., Kamhawi, S., et al. (2020). Implicating Bites From a Leishmaniasis Sand Fly Vector in the Loss of Tolerance in Pemphigus. JCI Insight 5 (23), 123861. doi: 10.1172/ jci.insight. 123861

Mondragon-Shem, K., Al-Salem, W. S., Kelly-Hope, L., Abdeladhim, M., AlZahrani, M. H., Valenzuela, J. G., et al. (2015). Severity of Old World Cutaneous Leishmaniasis Is Influenced by Previous Exposure to Sandfly Bites in Saudi Arabia. PloS Negl. Trop. Dis. 9 (2), e0003449. doi: 10.1371/ journal.pntd.0003449

Moraes, M. E., Fernandez-Vina, M., Lazaro, A., Diaz, L. A., Filho, G. H., Friedman, H., et al. (1997). An Epitope in the Third Hypervariable Region of the DRB1 Gene is Involved in the Susceptibility to Endemic Pemphigus Foliaceus (Fogo Selvagem) in Three Different Brazilian Populations. Tissue Antigens 49 (1), $35-$ 40. doi: 10.1111/j.1399-0039.1997.tb02707.x

Morris, R. V., Shoemaker, C. B., David, J. R., Lanzaro, G. C., and Titus, R. G. (2001). Sandfly Maxadilan Exacerbates Infection With Leishmania Major and Vaccinating Against it Protects Against L. Major Infect. J. Immunol. 167 (9), 5226-5230. doi: 10.4049/jimmunol.167.9.5226

Oliveira, F., Lawyer, P. G., Kamhawi, S., and Valenzuela, J. G. (2008). Immunity to Distinct Sand Fly Salivary Proteins Primes the Anti-Leishmania Immune Response Towards Protection or Exacerbation of Disease. PloS Negl. Trop. Dis. 2 (4), e226. doi: 10.1371/journal.pntd.0000226

Oliveira, F., Rowton, E., Aslan, H., Gomes, R., Castrovinci, P. A., Alvarenga, P. H., et al. (2015). A Sand Fly Salivary Protein Vaccine Shows Efficacy Against Vector-Transmitted Cutaneous Leishmaniasis in Nonhuman Primates. Sci. Transl. Med. 7 (290), 290ra90. doi: 10.1126/scitranslmed.aaa3043

Oliveira, F., Traore, B., Gomes, R., Faye, O., Gilmore, D. C., Keita, S., et al. (2013). Delayed-Type Hypersensitivity to Sand Fly Saliva in Humans From a Leishmaniasis-Endemic Area of Mali Is Th1-Mediated and Persists to Midlife. J. Invest. Dermatol. 133 (2), 452-459. doi: 10.1038/jid.2012.315

Qaqish, B. F., Prisayanh, P., Qian, Y., Andraca, E., Li, N., Aoki, V., et al. (2009). Development of an IgG4-Based Predictor of Endemic Pemphigus Foliaceus (Fogo Selvagem). J. Invest. Dermatol. 129 (1), 110-118. doi: 10.1038/jid.2008.189

Qian, Y., Clarke, S. H., Aoki, V., Hans-Filhio, G., Rivitti, E. A., and Diaz, L. A. (2009). Antigen Selection of Anti-DSG1 Autoantibodies During and Before the Onset of Endemic Pemphigus Foliaceus. J. Invest. Dermatol. 129 (12), $2823-$ 2834. doi: $10.1038 /$ jid.2009.184

Qian, Y., Jeong, J. S., Abdeladhim, M., Valenzuela, J. G., Aoki, V., Hans-Filhio, G., et al. (2015). IgE Anti-LJM11 Sand Fly Salivary Antigen may Herald the Onset of Fogo Selvagem in Endemic Brazilian Regions. J. Invest. Dermatol. 135 (3), 913-915. doi: 10.1038/jid.2014.430

Qian, Y., Jeong, J. S., Maldonado, M., Valenzuela, J. G., Gomes, R., Teixeira, C., et al. (2012). Cutting Edge: Brazilian Pemphigus Foliaceus Anti-Desmoglein 1 Autoantibodies Cross-React With Sand Fly Salivary LJM11 Antigen. J. Immunol. 189 (4), 1535-1539. doi: 10.4049/jimmunol.1200842 
Qian, Y., Jeong, J. S., Ye, J., Dang, B., Abdeladhim, M., Aoki, V., et al. (2016). Overlapping IgG4 Responses to Self- and Environmental Antigens in Endemic Pemphigus Foliaceus. J. Immunol. 196 (5), 2041-2050. doi: 10.4049/jimmunol.1502233

Remoue, F., Cisse, B., Ba, F., Sokhna, C., Herve, J. P., Boulanger, D., et al. (2006). Evaluation of the Antibody Response to Anopheles Salivary Antigens as a Potential Marker of Risk of Malaria. Trans. R Soc. Trop. Med. Hyg. 100 (4), 363-370. doi: 10.1016/j.trstmh.2005.06.032

Ribeiro, J. M., and Francischetti, I. M. (2003). Role of Arthropod Saliva in Blood Feeding: Sialome and Post-Sialome Perspectives. Annu. Rev. Entomol. 48, 7388. doi: $10.1146 /$ annurev.ento.48.060402.102812

Ribeiro, J. M., Katz, O., Pannell, L. K., Waitumbi, J., and Warburg, A. (1999). Salivary Glands of the Sand Fly Phlebotomus Papatasi Contain Pharmacologically Active Amounts of Adenosine and 5'-AMP. J. Exp. Biol. 202 (Pt 11), 1551-1559. doi: 10.1242/jeb.202.11.1551

Rock, B., Martins, C. R., Theofilopoulos, A. N., Balderas, R. S., Anhalt, G. J., Labib, R. S., et al. (1989). The Pathogenic Effect of IgG4 Autoantibodies in Endemic Pemphigus Foliaceus (Fogo Selvagem). N. Engl. J. Med. 320 (22), 1463-1469. doi: 10.1056/NEJM198906013202206

Rohousova, I., and Volf, P. (2006). Sand Fly Saliva: Effects on Host Immune Response and Leishmania Transmission. Folia Parasitol. (Praha) 53 (3), 161171. doi: $10.14411 /$ fp. 2006.022

Schwartz, B. S., Ford, D. P., Childs, J. E., Rothman, N., and Thomas, R. J. (1991). Anti-Tick Saliva Antibody: A Biologic Marker of Tick Exposure That Is a Risk Factor for Lyme Disease Seropositivity. Am. J. Epidemiol. 134 (1), 86-95. doi: 10.1093/oxfordjournals.aje.a115996

Sima, M., Ferencova, B., Warburg, A., Rohousova, I., and Volf, P. (2016). Recombinant Salivary Proteins of Phlebotomus Orientalis Are Suitable Antigens to Measure Exposure of Domestic Animals to Sand Fly Bites. PloS Negl. Trop. Dis. 10 (3), e0004553. doi: 10.1371/journal.pntd.0004553

Souza, A. P., Andrade, B. B., Aquino, D., Entringer, P., Miranda, J. C., Alcantara, R., et al. (2010). Using Recombinant Proteins From Lutzomyia Longipalpis Saliva to Estimate Human Vector Exposure in Visceral Leishmaniasis Endemic Areas. PloS Negl. Trop. Dis. 4 (3), e649. doi: 10.1371/journal.pntd.0000649

Sumova, P., Sima, M., Spitzova, T., Osman, M. E., Guimaraes-Costa, A. B., Oliveira, F., et al. (2018). Human Antibody Reaction Against Recombinant Salivary Proteins of Phlebotomus Orientalis in Eastern Africa. PloS Negl. Trop. Dis. 12 (12), e0006981. doi: 10.1371/journal.pntd.0006981

Tavares, N. M., Silva, R. A., Costa, D. J., Pitombo, M. A., Fukutani, K. F., Miranda, J. C., et al. (2011). Lutzomyia Longipalpis Saliva or Salivary Protein LJM19 Protects Against Leishmania Braziliensis and the Saliva of Its Vector, Lutzomyia Intermedia. PloS Negl. Trop. Dis. 5 (5), el169. doi: 10.1371/journal.pntd.0001169

Teixeira, C., Gomes, R., Collin, N., Reynoso, D., Jochim, R., Oliveira, F., et al. (2010). Discovery of Markers of Exposure Specific to Bites of Lutzomyia Longipalpis, the Vector of Leishmania Infantum Chagasi in Latin America. PloS Negl. Trop. Dis. 4 (3), e638. doi: 10.1371/journal.pntd.0000638

Tlili, A., Marzouki, S., Chabaane, E., Abdeladhim, M., Kammoun-Rebai, W., Sakkouhi, R., et al. (2018). Phlebotomus Papatasi Yellow-Related and Apyrase Salivary Proteins Are Candidates for Vaccination Against Human Cutaneous Leishmaniasis. J. Invest. Dermatol. 138 (3), 598-606. doi: 10.1016/j.jid.2017.09.043

Valenzuela, J. G., Belkaid, Y., Garfield, M. K., Mendez, S., Kamhawi, S., Rowton, E. D., et al. (2001). Toward a Defined Anti-Leishmania Vaccine Targeting Vector Antigens: Characterization of a Protective Salivary Protein. J. Exp. Med. 194 (3), 331-342. doi: 10.1084/jem.194.3.331

Valenzuela, J. G., Belkaid, Y., Rowton, E., and Ribeiro, J. M. (2001). The Salivary Apyrase of the Blood-Sucking Sand Fly Phlebotomus Papatasi Belongs to the Novel Cimex Family of Apyrases. J. Exp. Biol. 204 (Pt 2), 229-237. doi: 10.1242/jeb.204.2.229

Valenzuela, J. G., Garfield, M., Rowton, E. D., and Pham, V. M. (2004). Identification of the Most Abundant Secreted Proteins From the Salivary Glands of the Sand Fly Lutzomyia Longipalpis, Vector of Leishmania Chagasi. J. Exp. Biol. 207 (Pt 21), 3717-3729. doi: 10.1242/jeb.01185

Vinhas, V., Andrade, B. B., Paes, F., Bomura, A., Clarencio, J., Miranda, J. C., et al. (2007). Human Anti-Saliva Immune Response Following Experimental
Exposure to the Visceral Leishmaniasis Vector, Lutzomyia Longipalpis. Eur. J. Immunol. 37 (11), 3111-3121. doi: 10.1002/eji.200737431

Walsh, P., Brochado, M. J. F., Vernal, S., Machado, A. R., Turatti, A., de Paula, N. A., et al. (2017). Relationship Between Pemphigus and American Tegumentary Leishmaniasis: Insights From Serological and Genetic Profiles. Trans. $R$ Soc. Trop. Med. Hyg. 111 (8), 345-353. doi: 10.1093/trstmh/trx065

Warren, S. J., Arteaga, L. A., Rivitti, E. A., Aoki, V., Hans-Filho, G., Qaqish, B. F., et al. (2003). The Role of Subclass Switching in the Pathogenesis of Endemic Pemphigus Foliaceus. J. Invest. Dermatol. 120 (1), 104-108. doi: 10.1046/ j.1523-1747.2003.12017.x

Warren, S. J., Lin, M. S., Giudice, G. J., Hoffmann, R. G., Hans-Filho, G., Aoki, V., et al. (2000). The Prevalence of Antibodies Against Desmoglein 1 in Endemic Pemphigus Foliaceus in Brazil. Cooperative Group on Fogo Selvagem Research. N. Engl. J. Med. 343 (1), 23-30. doi: 10.1056/NEJM200007063430104

Wheat, W. H., Arthun, E. N., Spencer, J. S., Regan, D. P., Titus, R. G., and Dow, S. W. (2017). Immunization Against Full-Length Protein and Peptides From the Lutzomyia Longipalpis Sand Fly Salivary Component Maxadilan Protects Against Leishmania Major Infection in a Murine Model. Vaccine 35 (48 Pt B), 6611-6619. doi: 10.1016/j.vaccine.2017.10.039

Willen, L., Lestinova, T., Kalouskova, B., Sumova, P., Spitzova, T., Velez, R., et al. (2019). Field Study of the Improved Rapid Sand Fly Exposure Test in Areas Endemic for Canine Leishmaniasis. PloS Negl. Trop. Dis. 13 (11), e0007832. doi: 10.1371/journal.pntd.0007832

Willen, L., Mertens, P., and Volf, P. (2018). Evaluation of the Rsp03b Sero-Strip, a Newly Proposed Rapid Test for Canine Exposure to Phlebotomus Perniciosus, Vector of Leishmania Infantum. PloS Negl. Trop. Dis. 12 (8), e0006607. doi: 10.1371/journal.pntd.0006607

Xu, X., Oliveira, F., Chang, B. W., Collin, N., Gomes, R., Teixeira, C., et al. (2011). Structure and Function of a "Yellow" Protein From Saliva of the Sand Fly Lutzomyia Longipalpis That Confers Protective Immunity Against Leishmania Major Infection. J. Biol. Chem. 286 (37), 32383-32393. doi: 10.1074/jbc.M111.268904

Zahedifard, F., Gholami, E., Taheri, T., Taslimi, Y., Doustdari, F., Seyed, N., et al. (2014). Enhanced Protective Efficacy of Nonpathogenic Recombinant Leishmania Tarentolae Expressing Cysteine Proteinases Combined With a Sand Fly Salivary Antigen. PloS Negl. Trop. Dis. 8 (3), e2751. doi: 10.1371/ journal.pntd.0002751

Zaraa, I., Boussoffara, T., Ben Ahmed, M., Marzouki, S., Ben Hassouna, N., Sellami, M. K., et al. (2012). Exposure to Phlebotomus Papatasi and/or Leishmania Major: Possible Etiologic Link to Tunisian Pemphigus. J. Invest. Dermatol. 132 (2), 479-482. doi: 10.1038/jid.2011.291

Zimmermann, P., and Curtis, N. (2019). Factors That Influence the Immune Response to Vaccination. Clin. Microbiol. Rev. 32 (2), e00084-18. doi: 10.1128/ CMR.00084-18

Conflict of Interest: The authors declare that the research was conducted in the absence of any commercial or financial relationships that could be construed as a potential conflict of interest.

The handling Editor declared a past co-authorship with one of the authors JV.

Publisher's Note: All claims expressed in this article are solely those of the authors and do not necessarily represent those of their affiliated organizations, or those of the publisher, the editors and the reviewers. Any product that may be evaluated in this article, or claim that may be made by its manufacturer, is not guaranteed or endorsed by the publisher.

Copyright (c) 2022 Aoki, Abdeladhim, Li, Cecilio, Prisayanh, Diaz and Valenzuela. This is an open-access article distributed under the terms of the Creative Commons Attribution License (CC BY). The use, distribution or reproduction in other forums is permitted, provided the original author(s) and the copyright owner(s) are credited and that the original publication in this journal is cited, in accordance with accepted academic practice. No use, distribution or reproduction is permitted which does not comply with these terms. 